Revista aSEPHallus de Orientação Lacaniana Núcleo Sephora de Pesquisa sobre o Moderno e o Contemporâneo ISSN $1809-709 \mathrm{X}$

\title{
O ato de fugir de casa na adolescência: algumas hipóteses a partir de casos atendidos no projeto Caminho de Volta ${ }^{1}$
}

Claudia Figaro-Garcia

Doutora em Ciências pelo Instituto de Psicologia da Universidade de São Paulo; Psicóloga da Faculdade de Medicina da Universidade de São Paulo (FMUSP) (São Paulo, Brasil) Psicanalista, membro da Clínica Lacaniana de Atendimento e Pesquisa em Psicanálise (CLIPP) (São Paulo, Brasil), associada ao Instituto do Campo Freudiano (São Paulo, Brasil) Correspondente da Escola Brasileira de Psicanálise - Seção São Paulo (EBPSP) (São Paulo, Brasil)

Resumo: Nesse artigo serão discutidas algumas hipóteses para a ocorrência de fugas de casa na adolescência a partir dos casos atendidos no Projeto Caminho de Volta, tais como: a violência doméstica, os conflitos com o Outro familiar, as errâncias e passagens ao ato, as mudanças no real do corpo e o encontro com o Outro sexo. $\mathrm{O}$ ato de fugir se torna um desaparecimento quando a polícia é acionada pela família.

Palavras-chave: adolescência; fuga de casa; desaparecimento; psicanálise; projeto Caminho de Volta.

Le fuir de la maison dans l'adolescence: quelques hypothèses des cas du projet Caminho de Volta Dans cet article seront discutés quelques hypothèses pour l'occurence de fuites de la Maison a partir des cas qui sont observés dans le projet Caminho de Volta tels que: la violence domestique, les conflits avec le Autre familier, l'errance et les passages a l'acte, les transformations subies par le réel du corps et le défis pour rencontrer l'Autre sexe. L'act de fuir ne devient une disparition que lorsque la famille demande l'assistance de la police.

Mots-clés: adolescence; fuite; disparition; psychanalyse; projet Caminho de Volta.

\begin{abstract}
Running away from home in the adolescence: some hypotheses from the Caminho de Volta project cases

This article will discuss some hypotheses about the running away from home in the adolescence from cases of "Caminho de Volta" Project such as: domestic violence, the conflicts with the Other familiar, the wandering and the passages to the act, the changes of the real of the body and the encounter of the Other sex. The act of running away from home is not considered as a disappearance until the family seeks police assistance.
\end{abstract}

Keywords: adolescents; runaway; disappearance; psychoanalysis; Caminho de Volta project. 


\section{O ato de fugir de casa na adolescência: algumas hipóteses a partir de casos atendidos no projeto Caminho de Volta}

Claudia Figaro-Garcia

Durante a adolescência, o sujeito enfrenta alguns desafios tais como: as mudanças no real do corpo, o encontro com o Outro sexo, a busca de maior autonomia, lidar com os conflitos advindos do enigma de seu lugar junto ao desejo dos pais e as angústias de que a proporção sexual não existe entre os pares humanos. Os adolescentes podem apresentar diferentes sintomas psíquicos para lidar com a angústia presente nesses momentos, e a fuga de casa pode ser um desses sintomas. Como aponta Lacadée (2011, p. 263) "o corpo do adolescente é o lugar da experiência da falha do saber que leva o sujeito ao exílio, ou seja, a se distanciar da autoridade dos pais, às vezes ao preço de um ato separador". Mas a contemporaneidade, e com ela o declínio da função paterna na adolescência, também tem seus efeitos e "precipita o sujeito em uma perturbação tal que ele pode querer sair do mundo através de uma provocação ou de um ato" (Lacadée, 2011, p. 263).

No Brasil, a fuga ganha o estatuto de desaparecimento após a família fazer uma queixa na polícia e abrir um Boletim de Ocorrência (B.O). Em um levantamento realizado por Figaro-Garcia (2010), foi observado que no Estado de São Paulo, entre 2003 e 2008, foram abertos por volta de 9000 B.Os/ano de desaparecimento de menores de 18 anos (Tabela 1). Desses, 28\% são referentes a adolescentes do sexo masculino (entre 13 e 18 anos) e 48\% são de adolescentes do sexo feminino da mesma faixa etária. Porém, as ocorrências das adolescentes foram o dobro das ocorrências dos adolescentes - conforme os dados da Tabela 1.

Tabela 1 - Distribuição de boletins de ocorrência de desaparecimento lavrados no Estado de São Paulo

\begin{tabular}{|c|c|c|c|c|c|c|c|}
\hline ANO & $\begin{array}{l}\text { Homens } \\
\text { 0-7anos }\end{array}$ & $\begin{array}{c}\text { Mulheres } \\
\text { 0-7anos }\end{array}$ & $\begin{array}{c}\text { Homens } \\
\text { 08-12 anos }\end{array}$ & $\begin{array}{l}\text { Mulheres } \\
\text { 08-12 anos }\end{array}$ & $\begin{array}{c}\text { Homens } \\
\text { 13-18 anos }\end{array}$ & $\begin{array}{l}\text { Mulheres } \\
\text { 13-18 anos }\end{array}$ & TOTAL \\
\hline 2003 & 237 & 153 & 1.055 & 611 & 2.215 & 4.071 & 8.342 \\
\hline 2004 & 265 & 154 & 1.087 & 644 & 2.417 & 4.188 & 8.755 \\
\hline 2005 & 190 & 113 & 1.039 & 616 & 2.234 & 3.972 & 8.164 \\
\hline 2006 & 234 & 148 & 1.038 & 774 & 2.624 & 4.419 & 9.237 \\
\hline 2007 & 216 & 284 & 1.019 & 687 & 2.777 & 4.377 & 9.360 \\
\hline 2008 & 191 & 147 & 855 & 684 & 2.766 & 4.330 & 8.973 \\
\hline TOTAL & 1.333 & 999 & 5.074 & 4.016 & 15.033 & 25.357 & 52.831 \\
\hline
\end{tabular}

Fonte: DHPP - POLÍCIA CIVIL - PRODESP (material não publicado)

Cerca de $80 \%$ desses B.O. de desaparecimento são fugas de casa (Gattas \& Figaro-Garcia, 2007; Gattas, Figaro-Garcia \& Landini, 2011), sendo as mesmas o tipo mais comum de 
desaparecimento também em dados internacionais (Finkhelhor, Hotaling \& Sedlak, 1990; Hammer, Finkelhor \& Sedlak, 2002; Biehal \& Wade, 2002). O restante divide-se entre crimes de subtração (comumente conhecido como "rapto" ou "roubo") praticados pelos próprios pais, por conhecidos ou por desconhecidos, além de assassinatos, desaparecimentos por acidentes e desaparecimentos que há anos continuam ainda não solucionados.

Desde 2004 o desaparecimento de crianças e adolescentes tem sido estudado no Projeto Caminho de Volta da Faculdade de Medicina da USP, cujo objetivo inicial foi o de auxiliar na identificação dos desaparecidos menores de 18 anos por meio do cruzamento de informações genéticas inseridas em bancos de DNA. Uma vez observada a importância de conhecer as histórias e as condições desses desaparecimentos, a autora desenvolveu uma metodologia de atendimento clínico feita por psicólogos, que entrevistam os familiares dos desaparecidos e os desaparecidos, quando encontrados, sendo a mesma o tema de seu doutorado. As entrevistas são realizadas em uma delegacia de investigação de pessoas desaparecidas da capital (Figaro-Garcia, 2010).

Como o Caminho de Volta concebia um banco de dados para armazenar as informações das entrevistas, foi criado um questionário específico com perguntas sobre composição e histórico familiar, dados do desaparecido, dados sobre o desaparecimento e queixas anteriores ao desaparecimento, isto é, se havia histórico de violência doméstica, alcoolismo, adições, entre outros. Esse questionário é aplicado pelos psicólogos durante a chamada entrevista inicial com as famílias. Ao seu término são agendadas pelo menos mais 3 (três) entrevistas de retorno na própria delegacia, em intervalos de 15 dias (ou menos). Durante as entrevistas, o encontrado responde a outro questionário com perguntas sobre porque desapareceu, porque voltava para casa e desaparecia de novo, onde permaneceu nesse período, como se manteve, se sofreu algum tipo de violência e se gostaria de voltar para casa. Por se tratar de uma prática de psicanálise aplicada, uma vez que ocorrem dentro de uma delegacia, as entrevistas visam a escuta do sujeito, buscando localizar e apontar (quando possível) seu sintoma, como se implica com seu desejo, como se responsabiliza por suas ações e como responde à dinâmica familiar, no caso das crianças e adolescentes (FigaroGarcia, 2010).

Os casos são supervisionados semanalmente e encaminhados para a rede de atendimento psicossocial da cidade de São Paulo. A necessidade dos questionários não impede que as entrevistas sejam conduzidas como um dispositivo de escuta psicanalítica, onde se procura observar, por exemplo, os "efeitos de real" provocados pelo desaparecimento, que significantes são recorrentes no discurso dos entrevistados, que significantes são utilizados para representar o desaparecido, que lugar ele ocupa no desejo dos pais e se o desaparecimento ocorre várias vezes ou foi um evento episódico. As entrevistas também fornecem indicações sobre a demanda no discurso do familiar, uma vez que o desejo nem sempre é a de que o filho seja encontrado, mas sim a solução para outros problemas de ordem pessoal, conjugal ou com outros filhos. As possíveis razões para a 
ocorrência do desaparecimento aparecem de formas diferentes no discurso dos familiares e dos encontrados.

O presente artigo visa expor um panorama geral das possíveis hipóteses referendadas no trabalho de doutorado de Figaro-Garcia (2010) e apresentar, pela primeira vez, o significante "desfugir", construído pela autora a partir de sua experiência na escuta e supervisão desses casos. Tal significante foi construído por meio da junção dos significantes "desaparecer" e "fugir" para representar esse movimento do sujeito de sair de casa sem anuência dos pais, levando-os a buscar ajuda policial. Neste significante o prefixo "des" não tem o sentido de negação, separação ou ação contrária, mas foi usado como condensação entre dois significantes. O desfugir não é apenas um significante para representar uma fuga de casa, mas para representar também os efeitos da mesma e porque ela foi a escolha feita pelo sujeito em detrimento de outros caminhos possíveis. Essa construção é uma forma de dar uma nomeação para esse sintoma específico e será usado no decorrer do texto. $O$ presente artigo não vai trabalhar com as questões da multidisciplinaridade que envolve o Caminho de Volta e nem com os efeitos terapêuticos de sua prática clínica.

\section{Violência como modo de gozo nas famílias}

Nas entrevistas, as mães que compareceram com mais frequência do que os pais, justificaram a ausência deles por meio de dois motivos principais: ou eles estavam trabalhando ou não mantinham contato com a família. Em alguns casos, os pais perderam totalmente o contato com as parceiras quando souberam da gravidez, são pais que "desapareceram". Em outros, foram mães que perderam o contato com os pais biológicos de seus filhos depois de descobrirem que estavam grávidas, chegando até a mudar de Estado para não serem descobertas - mães que "desapareceram". Havia situações em que o paradeiro do pai era conhecido, mas ele não mantinha nenhum laço emocional com os filhos, não ajudava de forma alguma, não os registrava civilmente nem psiquicamente. Outro tipo de inexistência do pai é o fato das mães não saberem nem qual era o nome do homem que as tinha engravidado e acabaram repetindo esse sintoma com outros homens. Esses novos encontros, alguns sob efeito de drogas ou álcool, produziam filhos que nasciam sem sequer saber a identidade dos seus pais, qual a sua origem, qual a sua história.

A incógnita e o silêncio sobre a história paterna, se o pai estava vivo ou morto, a não inscrição psíquica ou civil de seu nome, podem desencadear sintomas diversos para o sujeito uma vez que o mesmo não consegue dar um sentido, não consegue simbolizar sua história. Já outras mães acabaram repetindo escolhas de parcerias nas quais impera a violência doméstica com elas e com os filhos biológicos (ou não), ou parcerias com dependência química (consumo de álcool e drogas), com envolvimento no tráfico de drogas ou em alguma outra infração penal. Esses exemplos podem ser considerados atos de violência contra o filho, deixando-o exposto a situações de maior vulnerabilidade psíquica e física. Foi observado que muitos pais não são capazes de lidar com as dificuldades no relacionamento com os filhos de outra maneira sem ser pela via da violência, da

Revista aSEPHallus de Orientação Lacaniana. Rio de Janeiro, 12(23), 45-59, nov. 2016 a abr. 2017. 
ameaça ou da indiferença. Em um levantamento realizados no Projeto Caminho de Volta observouse que em 717 famílias, a violência doméstica (que engloba maus tratos físicos, abuso sexual intrafamiliar, violência conjugal, violência psicológica e negligência) foi relatada em $68 \%$ dos casos (Gattas, Figaro-Garcia \& Landini, 2011).

Pode-se pensar que a violência se apresenta como um modo de gozo para essas famílias. Seguindo a conceituação de Lacan (1970/1992), após o Seminário 11, seu ensino e teorizações se dirigiram cada vez mais ao registro do real, ao que não é possível de ser simbolizado, significantizado pelo sujeito. O sintoma, até então concebido como mensagens endereçadas ao Outro, começa a ser marcado pelo modo de gozo singular de um sujeito. O gozo é da ordem do excesso, é aquilo de que o sujeito não quer abrir mão uma vez que ele tem uma sensação falsa de completude, e pelo qual paga um preço psíquico muito alto. O modo de gozo também se expressa por sua repetição, como será visto mais adiante.

Mas quais são os efeitos dessas violências, desse modo de gozo familiar para o psiquismo das crianças e adolescentes? O que Lacan (1969/2003) propõe sobre o sintoma da criança se estende ao sintoma do adolescente, ou seja, que ele "representa a verdade do casal parental" e o que há de sintomático nessas estrutras famíliares. Então, qual seria a verdade dessas famílias, muitas vezes monoparentais? Diante de quadros familiares violentos ou negligentes, uma primeira hipótese foi a de que talvez as crianças e adolescentes, ao desfugirem, tentassem colocar um limite naquilo em que os pais falharam ou que não tiveram condições de fazer de outro jeito. Se servem do desfugir como uma via de castração, ou seja, uma tentativa de fazer barra à violência pulsional na qual estavam submetidos. A rua parece ser menos perigosa do que continuar sob o mesmo teto; a saída de casa torna-se uma forma de sobrevivência física e psíquica para esses sujeitos.

A fuga de casa como consequência da violência doméstica sempre foi observada nos estudos da psicologia social ou da sociologia (Finkhelhor, Hotaling \& Sedlak, 1990; Apetkar, 1996; Hamer, Finkelhor \& Sedlak, 2002; Estes \& Weiner, 2005). Porém, apesar da violência doméstica ter sido presente em mais da metade dos casos atendidos, o desfugir enquanto sintoma psíquico amplia a discussão sobre o tema e não delimita a violência doméstica como principal motivo, principalmente por que muitas crianças e adolescentes não rompem definitivamente com o vínculo familiar, pois voltam espontaneamente para casa.

$\mathrm{Na}$ entrevista com os encontrados, seu discurso parecia encobrir a violência referida ou percebida no discurso dos familiares, talvez pelo temor em sofrer possíveis retaliações, mas também por não colocar na violência a principal razão de seu desfugir e sim em outros conflitos familiares. 0 desfugir parece mais uma forma de barrar a violência pulsional que pode ser diferente da violência doméstica. Esse é um dado interessante, pois muitas vezes o Outro social e jurídico coloca na violência doméstica a grande causa para inúmeros problemas com crianças e adolescentes, mas talvez haja outros conflitos na percepção dos filhos que sejam sentidos como mais graves do que a própria violência. 


\section{O filho-problema e o desejo do Outro familiar}

Mas havia relações familiares onde não imperavam esse modo de gozo e, independentemente de haver ou não violência, para muitos familiares os filhos não tinham solução, uma vez que "só dão trabalho", faziam com que os familiares "perdessem tempo" à sua procura, além de serem "ingratos", pois não reconheciam as coisas que lhe eram feitas. Os adolescentes, por sua vez, também tinham modos de gozo que levavam os pais a se queixarem com frequência sobre o consumo de drogas e álcool, além da prática de atos infracionais (participação em pequenos furtos, depredação de bem público ou privado, etc.). Outros se queixavam das dificuldades de relacionamento com os filhos e expressavam as frustrações quanto às escolhas de namorados ou amigos, à permanência por mais tempo nas ruas do que em casa, à dificuldade de colocação de limites, de conseguir que eles obedecessem às regras da casa, entre outras. Em seus relatos, expressavam a angústia por não saberem o que fazer frente às demandas, às escolhas e à desobediência dos adolescentes. Não raro, durante as entrevistas, surgiram demandas por "dicas" ou "conselhos" de como educar ou se relacionar com os filhos. Importante frisar que, para muitas famílias, o contato com o Caminho de Volta foi a primeira oportunidade que tiveram para falar sobre suas angústias a um sujeito suposto saber.

A adolescência coloca em cheque as expectativas dos pais frente ao desejo narcísico do filho ideal e à realidade de um sujeito com sua singularidade. Daí decorrem os conflitos que podem aparecer no dia a dia de qualquer família. Mas por que deixar a casa é a escolha desses sujeitos? $\mathrm{Na}$ entrevista com os encontrados (tanto os encontrados por terceiros como os que voltavam para casa de forma espontânea), alguns diziam que não haviam "fugido de casa", mas resolveram "dar um tempo" longe da família. Outros se irritavam pelo fato de os familiares terem colocado suas fotos em locais públicos para ajudar na sua localização ou terem ido até a polícia. Muitos usaram a gíria "pagar mico" para expressar seu constrangimento e diluir a gravidade do que haviam feito. Mas a grande maioria de suas queixas relacionam-se às proibições de namoros e amizades, às exigências para os afazeres domésticos, às discussões constantes sobre a escola e os estudos. Muitas das adolescentes reclamavam porque não queriam continuar se responsabilizando pelo cuidado da casa e dos irmãos menores. Outras queriam exercer sua sexualidade, usufruir de liberdade para namorar, ir e vir sem dar satisfações. A grande maioria se queixava da rigidez parental e da pressão para que ordens fossem cumpridas. Sendo assim, uma outra hipótese tem relação com a satisfação ou não do desejo do Outro familiar, ou seja, o desfugir pareceu caracterizar-se como a via possível para a realização de algo diferente na vida do sujeito, mesmo sendo uma opção que o colocasse em situação de maior vulnerabilidade. Seria uma forma de marcar sua existência independente do desejo de seus pais, e não ocupar o lugar a que foi destinado na família, ou seja, marcar a diferença entre seu ideal e o ideal dos pais, fazendo valer sua subjetividade, apesar dos possíveis riscos que poderiam vir a estar expostos (morar em lugares com péssimas condições de higiene e segurança, trabalhar para 
o tráfico de drogas ou ser aliciado para a exploração sexual infantil, entre outros). O desfugir parecia mostrar-se como resposta frente aos limites e exigências impostos pelos pais, uma forma de fazer valer seu desejo frente ao gozo excessivo do Outro.

Já em outros casos, o desfugir parecia uma forma encontrada pelo sujeito para solucionar o "sofrimento" que supostamente causava aos familiares, tantas vezes repetido nas entrevistas. Posição assumida a partir da marca dos significantes que the foram imputados, ou seja, serem "filhos-problema". Nas entrevistas diziam que não queriam mais "dar trabalho aos pais", e que dali para frente iriam mudar de comportamento. Nesses casos, pareceu que o desfugir caminhou justamente em direção à realização do desejo dos pais, isto é, do desejo de que esse filho-problema realmente fosse embora, uma vez que por ser o incômodo da família o melhor seria que seguisse sua vida longe de casa. Frases como "esse é o único filho que me dá trabalho" [sic], "não sei mais o que fazer com minha filha, ela tem tudo e nunca está satisfeita" [ sic], "desde pequeno ele apronta" [sic], "só até os cinco anos de idade eu tive paz com meu filho, depois minha vida virou um inferno" [sic], "ele faz isso para me atormentar e quando voltar quero interná-lo num hospital ou num abrigo" [sic], surgiram com frequência, mostrando mais uma vez como os filhos pareciam estar sempre no limite da paciência dos pais. A demanda por uma internação, ou por não querer que o filho voltasse para casa quando fosse encontrado, indicava o quanto esperavam que o Outro se responsabilizasse pelo adolescente, além de ressaltar a falta de implicação e de responsabilização no próprio ato de desfugir dos filhos.

Além do significante "filho que dá trabalho", o significante "mentiroso" surgiu de forma frequente na fala dos pais, sendo que a mentira não estava relacionada apenas com o desfugir (por exemplo, a adolescente que disse que iria até a casa da amiga, mas na verdade havia fugido com o namorado), mas com um universo maior de atitudes como mentir quanto a seu desempenho escolar ou quando solicitado a executar algo pedido pelos pais. Assim, esses adolescentes não pareciam encontrar outros recursos para satisfazer suas vontades e atender a demanda do Outro a não ser pela via da mentira. Mas por quê? Talvez nessas relações familiares só haja espaço para o engodo, para enganar e ser enganado, colocando pais e filhos em um jogo onde o gozo da descoberta da mentira e sua punição se repetem infindavelmente. $O$ significante da mentira remetia o filho a outros significantes no discurso de seus familiares, tais como, "irresponsável, sem-limites, doido, pouco confiável", o que acentuava ainda mais o significante filho-problema. Assim, ser o filho-problema talvez marcasse justamente a possibilidade de ter um lugar na família, de ter um reconhecimento, mesmo que pela via da exclusão. 0 desfugir seria a maneira de marcar uma presença na família.

\section{A repetição do desfugir}

As repetições não estavam presentes somente no jogo do mentir, em ser descoberto e punido ou em outros modos de gozo dos adolescentes, mas no próprio movimento do desfugir. A reincidência apareceu em $51 \%$ dos 717 casos do Caminho de Volta, no levantamento feito por 
Gattas, Figaro-Garcia e Landini (2011), ou seja, um pouco mais da metade. O que existe nesse modo de gozo do qual os adolescentes não conseguiram abrir mão? Por que uma vez longe da família, não permaneceram assim como muitas crianças em situação de rua? Porque precisavam retornar e desfugir novamente? A repetição já era algo constatado nos boletins de ocorrência e ficou mais presente a partir do momento em que as famílias foram entrevistadas. O que ela pode mostrar? Se o sintoma insistiu em repetir é porque essa foi a forma que o sujeito encontrou para dar conta de algo que ele não conseguiu resolver de outra maneira.

Freud (1920a/1976) relata a observação da brincadeira criada por seu neto pequeno, o Fort $D a$, que consistia em esconder um carretel atrás da cortina para depois puxá-lo e fazê-lo aparecer, controlando com essa repetição o movimento de sua mãe aparecer e desaparecer. Na questão das fugas talvez fosse possível imaginar que, em algumas famílias, o carretel poderia ser representado pela criança e que a mesma quisesse que sua mãe (ou outro responsável) controlasse a linha, puxando-a do lugar onde está para que ela rapidamente aparecesse. Havia familiares que pareciam "cortar" a linha deste carretel imaginário que a vinculava aos seus filhos e esses insistiam em aparecer apesar disto.

A repetição e o retorno para casa pareciam tentativas dos filhos em vislumbrar alguma mudança no seu cenário familiar, algo novo, uma nova realidade que pudesse ter sido criada na sua ausência. Uma senhora viúva, quando relatou a décima primeira fuga de seu filho único de oito anos, disse não entender porque ele fugia. Ela trabalhava o dia todo e ele ficava até às 9 horas da manhã sozinho em casa, momento da chegada de uma vizinha cuidadora. Talvez, o efeito de ser visto nas repetidas vezes em que era encontrado, pudesse marcar sua existência, marcar a possibilidade de fazer falta à mãe e verificar se ele tinha importância em sua vida. Vê-se nesse exemplo que a repetição não se restringiu às fugas, mas também ao movimento da mãe que parecia negar o chamado repetido de seu filho.

A repetição parece apontar para o gozo presente no jogo do desaparecer e ser encontrado, algo da ordem do gozar com o Outro. O desaparecido perpetuava nos familiares o movimento de preocupação quando desaparecia e de regozijo quando era encontrado. O filho podia ocupar o lugar metafórico do carretel do Fort Da nesse jogo do desaparecer/aparecer. O significante "dar trabalho", referendado na fala dos pais, também trouxe, em alguns casos, o sentido da onipotência do filho, ou seja, ser capaz de enlouquecer, de preocupar seus pais a ponto dos mesmos procurarem a polícia. Esse movimento dos pais pareceu revelar um triunfo que se repetiu no movimento de ser encontrado ou de se fazer encontrar. Na mesma lógica alguns pareceram utilizar esse jogo para comprovar se eram ou não amados por seus pais.

Em um texto de 2006, Lacadée trabalhou esse tema ao apresentar o personagem Fritz, de Robert Wesler. Um adolescente que, por se sentir rejeitado pela mãe e por sentir que ela prefere seu irmão, primeiro esconde-se no armário para ver se alguém se preocupa com sua ausência e depois decide ir embora de casa. Ao encontrar seu irmão no caminho, diz-lhe que a vida "é apenas 
um casaco em farrapos e que ele precisa remendá-lo", e sinaliza que iria para a lagoa (Lacadée, 2006, p. 28). O irmão então corre em direção à lagoa e vê o casaco e o chapéu de Fritz boiando na água. Fritz tinha os jogado na lagoa e depois havia subiu em uma árvore para verificar se a mãe choraria por ele.

A cena ficcional descrita por Lacadeé parece um elemento interessante para se pensar no movimento de "desaparecer" e "reaparecer". Uma hipótese possível é que talvez algumas crianças e adolescentes quisessem ver, assim como o jovem Fritz, o quão valiam no desejo de seus pais. Desfugir poderia ser um movimento de abrir uma brecha para verificar se eram amados, mesmo sendo "filhos incômodos" e justificado pelos significantes "ciumento" ou "mentiroso". Apesar dos constantes maus-tratos praticados pelo pai e pela queixa com relação à indiferença que a madrasta sentia por ele, um dos adolescentes entrevistados que já havia desaparecido oito vezes de casa não se distanciava de sua residência, dormindo na casa de vizinhos do prédio ou nas ruas do bairro. Monitorava o movimento da família à distância assim como outra adolescente que ficava escondida em um quartinho de um estacionamento privado em frente à sua casa.

Em alguns casos a compulsão à repetição no desfugir também apontou como o sujeito adolescente buscava sempre o mesmo objeto mais-de-gozar. Muitos meninos e meninas, que viviam em condições sociais melhores, submeteram-se a uma condição extremamente precária nas ruas. Outras se relacionavam com pessoas que repetiam modelos muito similares aos de seus familiares, colocando-os novamente em situação de vulnerabilidade. Alguns foram ameaçados, inseridos na criminalidade, na prostituição e no uso abusivo de drogas, além de se vincularem em relações amorosas extremamente problemáticas, resultando em gravidez precoce. Eles queriam permanecer assim, pois quando foram encontrados ou voltaram para casa, fugiam novamente em direção às mesmas condições. Nas entrevistas, verbalizavam sua preferência em ficar em lugares e em relações muito danosas a ficar em casa, mesmo sem haver histórico de violência doméstica ou de precariedade social. Assim, nas entrevistas, não adiantava apenas apontar a questão dos riscos a que eles se submetiam, mas escutar por que faziam isso, se conseguiam dar algum sentido para o desfugire por que escolheram permanecer assim. Obviamente, muitas dessas questões só poderiam ser melhor trabalhadas e tratadas nos atendimentos a longo prazo. Mas esse tempo de entrevistas inicias, em muitos casos, poderia funcionar como um "instante de ver" - possibilidade de localizar uma incógnita, um ponto de estranheza, de "sem sentido" que pudesse gerar algum desejo de saber sobre si e sobre seu mal-estar.

\section{Errâncias e passagens ao ato}

O sair de casa, em alguns casos, também pode se manifestar como errância e passagem ao ato. Ao retomar o caso da jovem paciente homossexual atendida por Freud (1920b/1976), Lacan (1963/2005) definiu a passagem ao ato como o momento de maior embaraço sentido pelo sujeito, aliado a um "acréscimo comportamental da emoção". No caso da jovem, ela "saiu de cena" ao pular 
da ponte após ter se deparado com o olhar de reprovação de seu pai, sendo em seguida tomada pela emoção do rompimento feito pela namorada. O desfugir, ao funcionar como uma passagem ao ato, parece refletir a única possibilidade que o sujeito encontra quando ele não recebe um retorno frente ao apelo que faz ao Outro, quando a função paterna não Ihe responde. Sem um posicionamento vindo do outro, o sujeito se perde. Pode-se pensar em uma errância, em um perderse no mundo sem a possibilidade de um enlace com o outro e com o Outro social. Lacan diz que a fuga é um exemplo semelhante à passagem ao ato:

A que chamamos fuga, no sujeito que nela se precipita, sempre mais ou menos colocado numa posição infantil, senão a essa saída de cena, à partida errante para o mundo puro, na qual o sujeito sai à procura, ao encontro de algo rejeitado, recusado em toda parte? Ele vira fumaça, como se costuma dizer, e, é claro, retorna, o que talvez lhe dê ensejo para ser valorizado. A partida é justamente a passagem da cena para o mundo. (Lacan, 1963, p. 130)

Um garoto de dez anos tentou, por várias vezes, se aproximar de seu pai que nunca o registrou e nem queria contato com ele. Na escola fez um desenho para o dia dos pais e disse para a mãe que iria entregá-lo pessoalmente junto com uma lembrança que havia comprado. A mãe não o impediu. Quando foi até a casa do pai para lhe entregar seus presentes, esse o mandou embora dizendo que não queria nada do filho. O garoto, que nunca tinha fugido, saiu caminhando pela rua sendo encontrado em um abrigo meses depois. Disse que alguém Ihe perguntou se poderia ajudálo e ele não falou onde morava nem o que tinha acontecido. 0 garoto saiu de cena após a rejeição paterna daquilo que queria dar a ele, seu amor. O pai não respondeu ao apelo do filho para que, ao se posicionar como pai, o posicionasse como filho. Frente ao real do vazio do lugar evidenciado pelo "não" paterno, restou ao menino "sair de cena". O garoto pareceu ter se confrontado como objeto para o Outro paterno e se identificou com esse objeto, ou seja, um objeto desprovido de valor fálico.

A errância no desfugir também pode envolver o fascínio pelo risco, por enfrentar desafios e aventuras, como por exemplo, viajar em trem de carga, pedir carona e ir para outras regiões do país, situações relatadas nas entrevistas. Lacadée (2006) citou o poeta francês do século XIX, Arthur Rimbaud, como o modelo de adolescente capaz de romper qualquer laço social e viver errante pelo mundo. No Caminho de Volta os adolescentes que se utilizam do significante "aventura", talvez o façam como uma forma camuflar a angústia. A aventura pode ser considerada uma forma de errância, mas nos casos atendidos não se tratava de uma errância pelo mundo, pois muitos voltam para casa em poucos dias ou semanas. O problema é, novamente, a onipotência adolescente que o faz acreditar que tem tudo sob controle, não dimensionado possíveis riscos. Muitas aventuras ocorrem por encontros marcados pela internet para conhecer um desconhecido e em alguns casos a família perde o contato e o caso entra para as estatísticas dos não solucionáveis. Ou por situações 
imprevisíveis, como se perder na mata ou trilhas, e se deparar com desconhecidos que os coloque em risco até de morte.

\section{Encontro com o Outro sexo}

A última hipótese trata das questões relacionadas ao sexual, ao corpo, ao encontro com o real do sexo e com o Outro sexo. As escolhas amorosas ou outras situações que não conseguem ser colocadas em palavras pelo sujeito podem provocar muita angústia. O não conseguir colocar em palavras aponta para algo da ordem do real, e novamente para a análise dos modos de gozo do sujeito dessa vez frente à não-relação ou à não proporção sexual - o que significa que, no humano, o encontro sexual com o parceiro não é instintivo, automático, determinado como nos animais. Há sempre uma incógnita com relação ao que o outro quer de mim, o que ele deseja e o que devo fazer para ser amado. O artigo de Stevens (2004) aborda essa dificuldade que começa na puberdade quando o sujeito experimenta o impasse de posicionar-se frente ao próprio corpo sexuado e ao outro sexo, ou seja, (não) saber o que fazer com as mudanças que seu corpo produz, o que fazer com as excitações sexuais que não se reduzem apenas ao prazer de órgão como na masturbação infantil, não saber como agir frente à sua escolha de objeto. 0 autor aborda o real do corpo biológico, um real orgânico que se manifesta pela elevação do nível hormonal nessa fase da vida, mas que também é marcado pela linguagem, ou seja, "esse real, mais que ser orgânico, é a emergência de um novo para o qual o sujeito não tem uma resposta pronta. Para dizer melhor, diante dessa eclosão, a fantasia do sujeito falha" (Stevens, 2004, p. 33).

$\mathrm{Na}$ puberdade, o corpo infantil que começa a se modificar pelos caracteres sexuais secundários, começa também a exercer fascínio no desejo do Outro e no desejo do próprio sujeito. Com a entrada cada vez mais precoce na vida sexual ativa e a alternância quase que compulsiva de parceiros (o famoso "ficar" adolescente) parece um movimento no sentido de resposta frente ao enigma da não-relação sexual. Essas experimentações que ele faz com sua sexualidade também provocam conflitos, pois, em alguns casos, geram filhos, abortos provocados, expulsões de casa e o desfugir. Talvez isso possa ser uma das explicações para os índices de desaparecimento que aumentam a partir dos 13 anos e duplicam entre as adolescentes do sexo feminino, como apontado anteriormente (Tabela 1). Até fevereiro de 2015, elas representavam mais da metade dos 1100 casos atendidos no Caminho de Volta, sendo 80\% com idades entre 13 e 17 anos. Os meninos representavam $63 \%$ na mesma faixa etária.

Um dado interessante das entrevistas com as adolescentes foi o fato de muitas não saberem ao certo se eram hétero, homo ou bissexuais. Essa dúvida advinha de uma relação com outra garota, que podia ser uma experimentação, uma curiosidade ou uma confirmação de sua escolha. Mas essa experimentação causava dúvidas em alguns casos, e o desfugir servia como uma tentativa de responder a isso, como Figaro-Garcia (2015) observou em 4\% das meninas e em 1,5\% dos meninos. Contudo, um trabalho mais criterioso sobre o significado do que é ser homem ou mulher para esses

Revista aSEPHallus de Orientação Lacaniana. Rio de Janeiro, 12(23), 45-59, nov. 2016 a abr. 2017. 
adolescentes e sobre questões relativas à masculinidade e à feminilidade seriam extremamente interessantes para que se possa pensar com mais cuidado sobre essas estatísticas antes de teorizações superficiais. Os sintomas de muitas adolescentes pareciam estar relacionados com a posição que elas ocupavam frente ao desejo de suas mães que se mostravam precisas ao descreverem os excessos pulsionais das filhas (ir a bailes funk, usar bebida e drogas, usar roupas decotadas ou "vulgares") e imprecisas quanto à identidade sexual delas. Não primavam ou não sabiam como dar suporte para a demanda de amor de suas filhas, sentida apenas como estorvo ou loucura. Expressavam que suas filhas não eram como desejavam imaginariamente e as filhas tentaram encontrar uma maneira de satisfazer o desejo materno, nem que fosse por meio de atuações ou até passagens ao ato.

\section{O que a clínica pode oferecer?}

Frente a essas hipóteses, e na impossibilidade de abordar no presente artigo o que poderia ser feito em termos de um trabalho de análise com esses adolescentes, Lacadée (2006) traz uma saída possível. Enfatiza a importância da compreensão sobre a fuga e propõe que o trabalho de análise seja no sentido de auxiliar o adolescente a encontrar um lugar onde ele possa endereçar seu sofrimento a fim de elaborar uma fórmula própria, já que a fórmula proposta pelo Outro é por ele rejeitada. $O$ autor aponta ainda que em "face do excedente de gozo que invade seu corpo e o deixa fora do discurso, a fuga ou a errância podem, de fato, representar uma última tentativa de inscrição em um laço social" (Lacadée, 2006, p. 22). Sua hipótese para esse gozo excedente é que, ao fracassar a possibilidade de tradução, de nomeação, de colocar em palavras o que the causa sofrimento, aparece o distúrbio de comportamento como "formação do inconsciente mais longa, mais continuada". Para ele, "ali onde o sintoma opera um enlace entre o significante e o corpo, uma prática de ruptura condena o sujeito a vagabundear, longe de qualquer inscrição significante que o ancore no campo do Outro (Lacadée, 2006, p. 22).

O desfugirnão pode ser considerado algo da ordem de uma "vagabundagem" do adolescente ou como um sintoma de menor importância. Ele pode sinalizar que algo não vai bem com o sujeito e/ou nas suas relações familiares, e por isso é preciso escutá-lo, bem como à sua família. Mas para além da escuta, ajudá-lo a colocar em palavras seu sofrimento. Lacadeé (2006) critica a ideia de que as fugas sejam sinais de delinquência e que os adolescentes devam ser submetidos a tratamentos comportamentais e educativos para serem corrigidos. Essa ideia esteve fortemente presente no discurso das famílias entrevistadas quando se referiram à necessidade de internação do filho para modificar seu comportamento. Para Lacadée, as fugas e errância

[...] são sintomas que põe em evidência uma clínica do ideal do eu, ligada à função do nome-do-pai. O nome-do-pai introduz a constituição de ideais a partir do processo de identificação e abre a construção, pelo sujeito, de sua resposta singular.

Revista aSEPHallus de Orientação Lacaniana. Rio de Janeiro, 12(23), 45-59, nov. 2016 a abr. 2017. 
O ideal do eu equivale ao ponto de capitonê que estabiliza o sentimento da vida, que dá ao sujeito seu lugar no outro e sua fórmula. (Lacadée, 2006, p. 25)

As várias hipóteses levantadas no trabalho apontam para os diferentes sentidos que 0 fenômeno do desfugir de crianças e adolescentes podem envolver. Apesar das particularidades das histórias, a questão do lugar que essas crianças e adolescentes ocupam no desejo dos pais/responsáveis indica um aspecto importante nessas configurações familiares. Talvez, por se sentirem como "filhos-problema sem solução", desfugir poderia ser a ação libertadora do incômodo provocado nos pais ao mesmo tempo que uma via de garantir um lugar em seu desejo, nem que seja o lugar do desaparecido que fugiu. Por outro lado, o desfugirserve para marcar um lugar próprio frente ao desejo dos pais, para se diferenciar e garantir sua autonomia enquanto sujeitos, apesar dos possíveis riscos que possam encontrar. $\mathrm{O}$ ato de desfugir parece configurar endereçamentos ao Outro familiar, cuja resposta é a busca pela ajuda policial, mas não buscar o que levou o filho(a) a desaparecer e se implicar com isso. No discurso das crianças e adolescentes muitos responderam que desejavam voltar para casa, mas que algo deveria mudar na família. Expressavam sua necessidade de sentir um movimento dos pais em sua direção, um investimento psíquico a partir da construção de outro olhar sobre eles e não mais o olhar sobre o "filho-incômodo".

A repetição no desfugir marca um modo de gozo dos adolescentes, possuindo sentidos particulares em cada um. E também aponta para diferentes objetos mais-de-gozar, que podem leválos a situações de extremo risco físico e psíquico. As angustias provocadas pelo real da não-relação sexual e pelo encontro com o real do sexo e com o Outro sexo também podem facilitar o desfugir como uma tentativa de dar conta das possíveis dúvidas ou demandas em usufruir do corpo e de sua sexualidade longe da família.

A intervenção por meio da análise pode ser o início de um processo de construção de fórmulas próprias e de se colocar noutra posição no Outro familiar que não apenas o "filho-incômodo". Ou seja, por meio do trabalho de análise, descobrir o que ele pode fazer criativamente com seu sintoma e sem se colocar em risco para enfrentar os impasses que a vida lhe apresenta não optando somente pelo desfugir. Essas podem ser direções no tratamento analítico.

\section{Nota:}

${ }^{1}$ Trabalho realizado no "Projeto Caminho de Volta: tecnologia busca de crianças e adolescentes desaparecidos", desenvolvido na Faculdade de Medicina da Universidade de São Paulo. Foi baseado na tese de doutorado da autora, intitulada "Uma proposta de prática psicológica para casos de desaparecimento de crianças e adolescentes", defendida em 2010 no Instituto de Psicologia da Universidade de São Paulo, orientada pela Profa. Dra. Eliana Herzberg.

Revista aSEPHallus de Orientação Lacaniana. Rio de Janeiro, 12(23), 45-59, nov. 2016 a abr. 2017. 


\section{Referências Bibliográficas}

Apetkar, L. (1996). Crianças de rua nos países em desenvolvimento: uma revisão de suas condições. Psicologia: Reflexão e Crítica, 9(1), 153-184. Rio Grande do Sul: UFRS.

Biehal, N. \& Wade, J. (2000, abr.). Going missing from residential and Foster Care: linking biographies and contexts. British Journal of Social Work, 30(2), 211-225. United Kingdom: Oxford University Press.

Estes, R. \& Weiner, N. (2005). The commercial sexual exploitation of children in the United States. In S. W. Cooper; R. Estes; A. P. Giardino; N. D. Kellogg, \& V. I Vieth, Medical, legal \& science aspects of child sexual exploitation. A comprehensive review for pornography, prostitution and internet crimes (Vol. 1, pp. 95-128). St. Louis: G.W. Medical.

Ferreira, T. (2000). Os meninos e a rua - o psicólogo e os impasses da assistência. Psicologia: Ciência e Profissão, 20(1), 2-17. Brasília: CFP.

Figaro-Garcia, C. (2010). Uma proposta de prática psicológica para casos de desaparecimento de crianças e adolescentes. (Tese de Doutorado). Instituto de Psicologia da Universidade de São Paulo, São Paulo.

Figaro-Garcia, C. (2015, set.). Meninas que desaparecem, suas mães e a questão homoerótica. 0 império das imagens. VII Encontro Americano de Psicanálise de Orientação Lacaniana (ENAPOL), São Paulo.

Finkelhor, D.; Hotaling, G. \& Sedlak, A. (1990). Missing abducted, runaway and thrownaway children in America. Washington, DC: US Department of Justice. Recuperado de http://www.ncjrs.gov/html/ojjdp/nismart.

Freud, S. (1976a). Além do princípio do prazer. Edição standard brasileira das obras psicológicas completas de Sigmund Freud (Vol. XVIII). Rio de Janeiro: Imago (Trabalho original publicado em 1920).

Freud, S. (1976b). A psicogênese de um caso de homossexualismo numa mulher. Edição standard brasileira das obras psicológicas completas de Sigmund Freud (Vol. XVIII). Rio de Janeiro: Imago (Trabalho original publicado em 1920).

Gattas, G. J. F. \& Figaro-Garcia, C. (2007). Caminho de Volta: tecnologia na busca de crianças e adolescentes desaparecidos no Estado de São Paulo. São Paulo: Secretaria Especial de Direitos Humanos: CONANDA - Conselho Nacional dos Direitos da Criança e do Adolescente.

Gattás, G. J. F.; Figaro-Garcia, C.; Landini, T. S. (2011). Desaparecimento e exploração sexual de crianças e adolescentes: relato de pesquisa. São Paulo: Ed do Autor.

Hammer, H.; Finkelhor, D.; Sedlak, A. (2002). Runaway/Thrownaway Children: National Estimates and Characteristics. Recuperado de http://www.ncjrs.gov/html/ojjdp/nismart/04/.

Lacadée, P. (2006, nov.). Fuga e errância na clínica com adolescentes. Carta de São Paulo - Boletim da Escola Brasileira de Psicanálise, 2, 21-32. São Paulo: EBP.

Lacadée, P. (2011, set.). A clínica da língua e do ato nos adolescentes. Responsabilidades, 1(2), 253-

Revista aSEPHallus de Orientação Lacaniana. Rio de Janeiro, 12(23), 45-59, nov. 2016 a abr. 2017. 
268.

http://www8.tjmg.jus.br/presidencia/programanovosrumos/pai pj/revista/edicao02/7.pdf.

Lacan, J. (1992). Saber, meio de gozo. O seminário, livro 17: o avesso da psicanálise. Rio de Janeiro: Jorge Zahar (Trabalho original publicado em 1970).

Lacan, J. (2003). Nota sobre a criança. Outros escritos. Rio de Janeiro: Jorge Zahar (Trabalho original publicado em 1969).

Lacan, J. (2005). Passagem ao ato e acting out. O seminário, livro 10: a angústia. Rio de Janeiro: Jorge Zahar (Trabalho original publicado em 1963).

Citacão/Citation: Figaro-Garcia, C. (nov. 2016 a abr. 2017). 0 ato de fugir de casa na adolescência: algumas hipóteses a partir de casos atendidos no projeto Caminho de Volta. Revista aSEPHallus de Orientação Lacaniana, 12(23), 45-59. Disponível em www.isepol.com/asephallus. doi: 10.17852/1809-709x.2019v12n23p45-59.

Editor do artigo: Tania Coelho dos Santos.

Recebido/Received: 29/11/2016/11/29/2016.

Aceito/Accepted: 18/02/2017 / 02/18/2017.

Copyright: (c) 2013 Associação Núcleo Sephora de Pesquisa sobre o moderno e o contemporâneo. Este é um artigo de livre acesso, que permite uso irrestrito, distribuição e reprodução em qualquer meio, desde que o autor e a fonte sejam citados/This is an open-access article, which permites unrestricted use, distribution, and reproduction in any medium, provided the author and source are credited. 